\title{
The use of Model Predictive Control (MPC) in the optimal distribution of electrical energy in a microgrid located in southeastern of Spain: A case study simulation
}

\author{
César Hernández-Hernández ${ }^{1}$, Francisco Rodríguez ${ }^{1}$, José Carlos Moreno ${ }^{1}$, Paulo Renato da Costa Mendes ${ }^{2}$ and \\ Julio Elías Normey-Rico² \\ ${ }^{1}$ Department of Informatics, Agrifood Campus of International Excellence ciaA3, CIESOL Research Center on Solar \\ Energy, University of Almeria, 04120 Almeria (Spain) \\ e-mail: chdezh@ual.es, frrodrig@ual.es,jcmoreno@ual.es \\ ${ }^{2}$ Federal University of Santa Catarina, Florianopolis, Brazil \\ e-mail: paulocrm@hotmail.com,julio.normey@ufsc.br
}

\begin{abstract}
The microgrids allow the integration of renewable sources of energy such as solar and wind and distributed energy resources such as combined heat and power, energy storage, and demand response. In addition, the use of local sources of energy to serve local loads helps reduce energy losses in transmission and distribution, further increasing efficiency of the electric delivery system. In this paper, the optimization problem of the energy in a microgrid (MG) located in southeastern of Spain, with Energy Storage System (ESS), which exchanges energy with the utility grid is developed using Model Predictive Control techniques. System modelling use the methodology of the Energy Hubs. The MPC techniques allow maximizing the economic benefit of the microgrid and to minimize the degradation of storage system.
\end{abstract}

\section{Key words}

Microgrid, Energy Hubs, Model Predictive Control.

\section{Introduction}

Nowadays, and in the future, system of electricity generation and distribution should be distributed intelligent, renewable and adaptable; these requirements will drive and evolution of the conventional electricity grid for future smart grids. The concept of MG focuses primarily on integration of distributed renewable energy sources, stationary storage batteries and methodologies for management and control, as is showed in [1]-[6]. The use of strategies control can provide optimal distribution of electricity to consumers.

In literature, there are several methods and applications on MGs, in [8] the basic structure of an MG is presented and is discussed about control techniques on MGs. In [9] the authors make a review of the latest documents related to the use of hybrid energy storage systems (HESS) that facilitate the introduction of renewable energy sources (RES) in MGs. In [10] a summary of the approaches (system configuration, unit size, control and energy management) available and currently being investigated for the optimal design of RES hybrid system is presented.
In general, microgrids management is carried out by heuristic algorithms [11], [12], although there are applications that use MPC strategies, such as those presented in [13] and [14].

The objective of this paper is to present a simulation of case study using MPC strategies and the methodology of the energy hubs for optimizing the energy distribution in a MG. The algorithm used performs the management of the use of renewable energy sources, storage and the purchase and sale of electric power to the external network.

The simulation have been performed using real data. In this paper it can be seen the benefit of the use of MPC techniques in an MG, where it makes use of renewable resources and the storage system more efficiently. In addition, the real price of energy $(€ / \mathrm{kWh})$ available in the electric market has been considered.

This paper is organized as follows: in section 2, the microgrid and the implemented methodology are presented; in section 3, the results and discussions are presented, and finally, in section 4 the conclusions are outlined.

\section{Materials and methodology}

The MG is integrated by a PV system, an electric vehicle in which their batteries can be used as an energy storage system, and two load systems (a building and a greenhouse). The Figure 1 shows the microgrid. Additionally, the microgrid has a connection to the utility grid allowing the purchase and sale of energy when is necessary.

\section{A. Materials}

The greenhouse. The greenhouse studied on this paper is a greenhouse multispan 'Parral type' (see Figure 2), with a surface area of $877 \mathrm{~m}^{2}$, oriented to the N-S direction. 


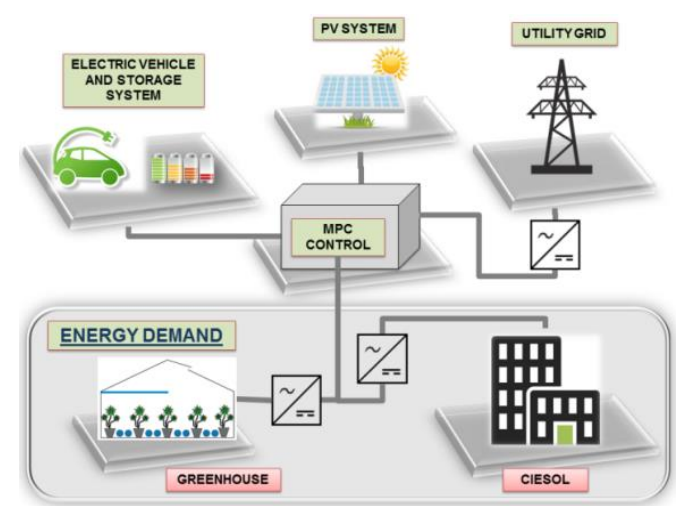

Fig. 1. Micro-Grid.

The facilities are placed on the experimental station of Cajamar Foundation, 'Las Palmerillas', at the municipal term of 'El Ejido', on Almeria, at the S-E of Spain [15]. The greenhouse has lateral and cenital ventilations powered through independent motors AC, aerothermo, heating system by hot water pipes fed with biomass, an enrichment system of $\mathrm{CO}_{2}$ created by the biomass burning, shade nets and systems of feeding for water and nutrients. It is equipped with a measure equipment of 52 variables and is designed to develop identification tests and to implement strategies of climate control, of fertigation and electric power. Furthermore, the greenhouse has sensors of energy demand (SINEAX M 561) programmable with RS-232 interface that are used by a computer with appropriate software [16].

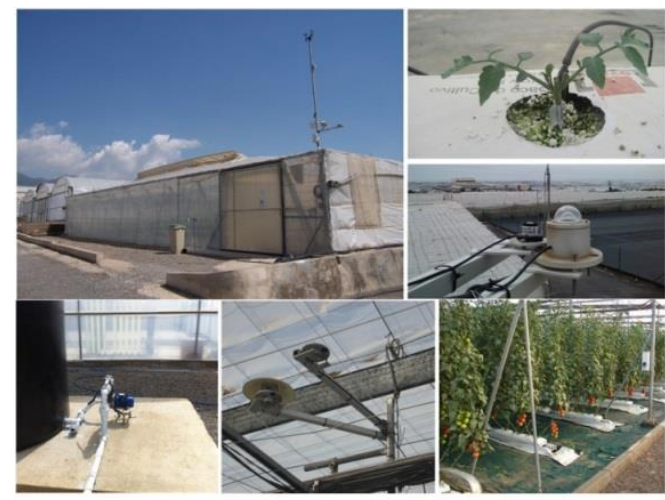

Fig. 2. Greenhouse.

Building CIESOL. The CDdI-CIESOL-ARFRISOL building is a solar energy research centre which is located inside the Campus of the UAL (University of Almeria) at the southeast of Spain. It is distributed in two different floors with a total surface of $1071.92 \mathrm{~m}^{2}$, composed by six offices, all of them with east orientation and located in the ground floor, with the exception of the main office which is placed in the upper floor, eight laboratories which face north (four located in the ground floor and devoted to 'Solar Chemistry', and the other four are placed in the upper floor, two for the 'Modeling and Automatic Control unit', and the remaining for the 'Evaluation of Solar Resources unit'), a plant where a high efficiency boiler and an absorption machine are located, and finally, rooms for employees of the centre such as the kitchen and the toilets as is showed in the Figure 3.

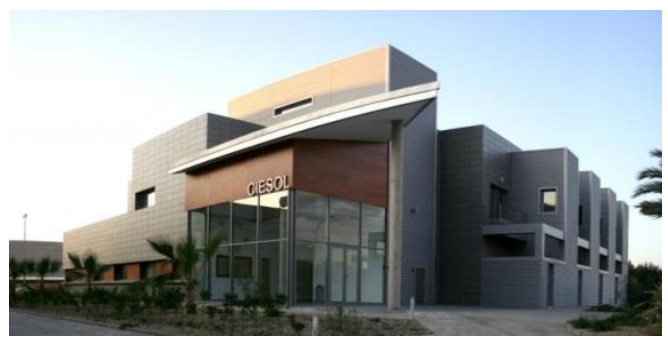

Fig. 3. Building CIESOL.

$P V$ system. The PV system is made up of several sets located at the University of Almeria. One of this sets (see Figure 4) is located on the sloping roof of the building CIESOL whit the following characteristics: the total number of modules is 4 associated in 3 sets of 14 panels/series with a unit capacity of $222 \mathrm{Wp} /$ panel, forming a photovoltaic field of $9.324 \mathrm{kWp}$. The total set of the University of Almeria that comprising the PV system forms a photovoltaic field of approximately 110 $\mathrm{kWp}$ with an efficiency of $80 \%$.

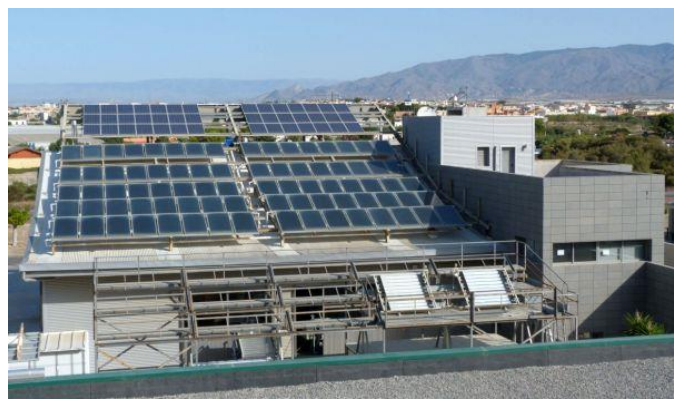

Fig. 4. PV system.

Batteries. The batteries of the electric vehicle (Figure 5) that have been used in this MG are Green Saver model, with a total capacity of $C=20 \mathrm{kWh}$ and an efficiency of charging $\eta_{\mathrm{BAT}_{\mathrm{CH}}}=0.8$ and discharging $\eta_{\mathrm{BAT}_{\mathrm{DISCH}}}=$ 0.7 , respectively.

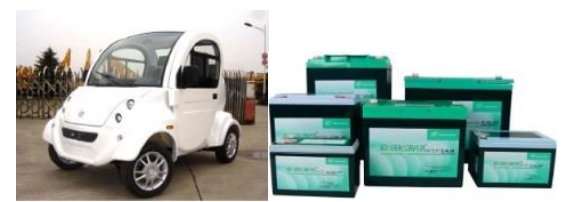

Fig. 5. Electric vehicle and batteries.

B. Methodology

The methodology of energy hubs to be used in this paper has been presented in [16] and [17]. An Energy Hub is defined as the interface between energy production, consumers and the transmission line. From the point of view of the system of Energy a hub can be identified as a unit that provides the following features: (1) power input and output; (2) energy conversion; (3) energy storage. Some of the main features of the Hubs are:

- Within energy hubs, losses occur only in converter and storage elements.

- If not mentioned explicitly, unidirectional power flow from the inputs to the outputs of the converters is assumed. 
- Power flow through converter devices is characterized through power and energy efficiency only, no other quantities are used.

This methodology is summarized as follows: a single converter converts, at time instant $\mathrm{k}$, a generic $\mathrm{r}$ input flow $u_{r}^{L}(k)$ of a generic hub in a $p$ output flow $y_{p}(k)$, where superscript $\mathrm{L}$ is associated to converter input flows. Input-output conversion is defined through the so called coupling factors $\gamma_{\mathrm{p}, \mathrm{r}}^{\mathrm{L}}$ which correspond to converters steady-state conversion efficiency between input and output flows:

$$
\mathrm{y}_{\mathrm{p}}(\mathrm{k})=\gamma_{\mathrm{p}, \mathrm{r}}^{\mathrm{L}} \mathrm{u}_{\mathrm{r}}^{\mathrm{L}}(\mathrm{k})
$$

If we have several converters, it can be written as follows

$$
\underbrace{\left[\begin{array}{c}
\mathrm{y}_{1}(\mathrm{k}) \\
\vdots \\
\mathrm{y}_{n_{p}}(\mathrm{k})
\end{array}\right]}_{\mathrm{y}_{\mathrm{i}}(\mathrm{k})}=\underbrace{\left[\begin{array}{ccc}
\gamma_{1,1}^{\mathrm{L}} & \cdots & \gamma_{1, \mathrm{r}}^{\mathrm{L}} \\
\vdots & \ddots & \vdots \\
\gamma_{\mathrm{p}, 1}^{\mathrm{L}} & \cdots & \gamma_{\mathrm{p}, \mathrm{r}}^{\mathrm{L}}
\end{array}\right]}_{\Gamma_{\mathrm{i}}^{\mathrm{L}}} \underbrace{\left[\begin{array}{c}
\mathrm{u}_{1}(\mathrm{k}) \\
\vdots \\
\mathrm{u}_{n_{r}}(\mathrm{k})
\end{array}\right]}_{\mathrm{u}_{\mathrm{i}}^{\mathrm{L}}}
$$

where $\Gamma_{\mathrm{i}}^{\mathrm{L}}$ is the converter coupling matrix.

Following the formulation, and from a discrete-time point of view, internal storage state $x_{i, s}$ at sampling time $\mathrm{k}+1$ depends on the state at previous sample $\mathrm{k}$ and on the total exchanged flow $\breve{\mathrm{u}}_{\mathrm{i}, \mathrm{s}}^{\mathrm{E}}(\mathrm{k})$ during the period $\Delta \mathrm{T}$ ranging from $\mathrm{k}$ and $\mathrm{k}+1$, where the values of inputoutput flow steady state is described by the relation:

$$
\breve{\mathrm{u}}_{\mathrm{i}, \mathrm{s}}^{\mathrm{E}}(\mathrm{k})=\mathrm{e}_{\mathrm{i}, \mathrm{s}}(\mathrm{k}) \mathrm{u}_{\mathrm{i}, \mathrm{s}}^{\mathrm{E}}(\mathrm{k})
$$

where $e_{i, s}(k)$ is the efficiency of the $i, s$ interface charging/discharging Hub, wich describes the energy exchange between the system and the storage. This factor depends on the direction of flow exchanged as follows:

$$
e_{i, s}=\left\{\begin{array}{ll}
e_{i, s}^{+}, \quad \text { if } u_{i, s}^{E} \geq 0 \quad \text { (charging) } \\
e_{i, s}^{-}, \quad \text { othercase }
\end{array} \quad\right. \text { (discharging) }
$$

where $e_{i, s}^{+}$and $e_{i, s}^{-}$are the charging and discharging efficiency, respectively ([18], [19]). Assuming $\breve{\mathrm{u}}_{\mathrm{i}, \mathrm{s}}^{\mathrm{E}}(\mathrm{k})$ to remain constant during $\Delta \mathrm{T}$ :

$$
\begin{aligned}
\mathrm{x}_{\mathrm{i}, \mathrm{s}}(\mathrm{k}+1)= & \mathrm{x}_{\mathrm{i}, \mathrm{s}}(\mathrm{k})+\int_{\mathrm{k}}^{\mathrm{k}+1} \breve{\mathrm{u}}_{\mathrm{i}, \mathrm{s}}^{\mathrm{E}}(\mathrm{t}) \mathrm{dt}=\mathrm{x}_{\mathrm{i}, \mathrm{s}}(\mathrm{k})+ \\
& \breve{\mathrm{u}}_{\mathrm{i}, \mathrm{s}}^{\mathrm{E}}(\mathrm{k})^{\mathrm{k}} \Delta \mathrm{T}
\end{aligned}
$$

If we consider that we have several storage systems

$$
\underbrace{\left[\begin{array}{c}
\mathrm{x}_{\mathrm{i}, 1}(\mathrm{k}+1) \\
\vdots \\
\mathrm{x}_{\mathrm{i}, \mathrm{n}_{\mathrm{s}}}(\mathrm{k}+1)
\end{array}\right]}_{\mathrm{x}_{\mathrm{i}}(\mathrm{k}+1)}=\underbrace{\left[\begin{array}{c}
\mathrm{x}_{\mathrm{i}, 1}(\mathrm{k}) \\
\vdots \\
\mathrm{x}_{\mathrm{i}, \mathrm{n}_{\mathrm{s}}}(\mathrm{k})
\end{array}\right]}_{x_{i}(k)}+\underbrace{\left[\begin{array}{ccc}
\mathrm{e}_{\mathrm{i}, 1}(\mathrm{k} & & \\
& \ddots & \\
& & \mathrm{e}_{\mathrm{i}, \mathrm{n}_{\mathrm{s}}}(\mathrm{k}
\end{array}\right]}_{\Lambda_{\mathrm{i}}^{\mathrm{E}}(\mathrm{k})} \underbrace{\left[\begin{array}{c}
\mathrm{u}_{\mathrm{i}, 1}^{\mathrm{E}}(\mathrm{k}) \\
\vdots \\
\breve{\mathrm{u}}_{\mathrm{i}, \mathrm{n}_{\mathrm{s}}}^{\mathrm{E}}(\mathrm{k})
\end{array}\right]}_{\mathrm{u}_{\mathrm{i}}^{\mathrm{E}}(\mathrm{k})}
$$

Then, a simple hub can be represented by the following condensed form as:

$$
\begin{gathered}
x_{i}(k+1)=x_{i}(k)+\Lambda_{i}^{E}(k) u_{i}^{E}(k) \\
y_{i}(k)=\Gamma_{i}^{L} u_{i}^{L}(k)
\end{gathered}
$$

\section{System modelling and control algorithm}

The plant model consists of two parts: on the one hand, following the equation (5), the evolution of the state variable $\left(S O C_{B A T}\right)$ of the microgrid is described by the linear model:

$$
\begin{aligned}
S O C_{B A T}(k+1)= & S O C_{B A T}(k)+\frac{\eta_{B A T_{C H}} \cdot P_{B A T_{C H}}(k) \cdot T_{S}}{C_{B A T}}+ \\
& \frac{\eta_{B A T_{D I S C H} \cdot P_{B A T_{D I S C H}}(k) \cdot T_{S}}}{C_{B A T}}
\end{aligned}
$$

Where $\eta_{B A T_{C H}}$ and $\eta_{B A T_{D I S C H}}$ are the efficiency of charge and discharge of the battery, respectively. $T_{S}$ is the simple time, $C_{B A T}$ is the battery capacity and $P_{B A T_{C H}}$ and $P_{B A T_{D I S C H}}$ are the charge and discharge power of batteries at time $t=k$ and $S O C_{B A T}$ is the State Of Charge of the batteries.

On the other hand, it is considered a remaining power at time $t=k$ of subsystems that integrate MG as follows:

$$
P_{\text {rem }}(k)=P_{p v}(k)-\operatorname{Load}(k)
$$

Where $\operatorname{Load}(k)=P_{C I E}(k)+P_{g h}(k) . \quad P_{p v}(k), \quad P_{C I E}(k)$ and $P_{g h}(k)$ are the energy production of the PV system and energy demand of the building CIESOL and the greenhouses that comprise a hectare of land, respectively. The Figure 6 shows the control diagram.

The input vector to MG is defined according to:

$u=\left[\begin{array}{lllll}P_{\text {solar }} & P_{\text {GridPurch }} & P_{\text {Gridsale }} & P_{B A T_{C H}} & P_{B A T_{D I S C H}}\end{array}\right]^{T}$

Where $P_{\text {solar }}$ is the generated solar power, $P_{\text {GridPurch }}$ and $P_{\text {Gridsale }}$ are the purchase and sale of energy to the utility grid, respectively.

Therefore, the MG can be modeled as a single hub in a condensed form as:

$$
\begin{aligned}
& x(k+1)=A x(k)+\Lambda u(k) \\
& y(k)=\Gamma u(k)
\end{aligned}
$$

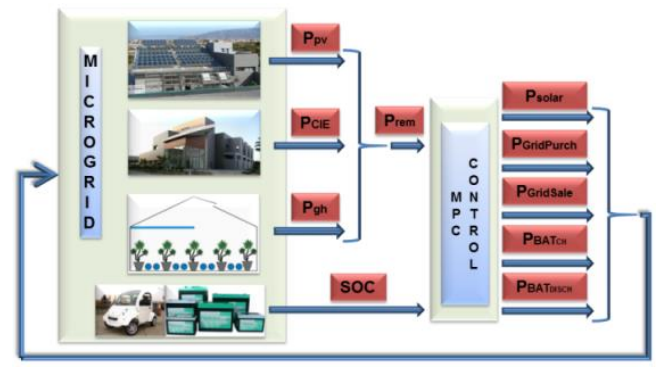

Fig. 6. Microgrid plant model and controller.

Where

$$
\begin{aligned}
A & =[1] \\
\Lambda & =\left[\begin{array}{lllll}
0 & 0 & 0 & \frac{\eta_{B A T_{C H}}}{C_{B A T}} & \frac{\eta_{B A T_{D I S C H}}}{C_{B A T}}
\end{array}\right] \\
\Gamma & =\left[\begin{array}{lllll}
\eta_{\text {solar }} & 1 & -1 & -1 & -1
\end{array}\right]
\end{aligned}
$$


and $\eta_{\text {solar }}$ is the conversion efficiency of solar energy.

The controller is designed to achieve economic optimization of the microgrid and make a good management of the use of batteries and determine the exact time of loading. The MPC is implemented this aim function:

$$
\begin{array}{r}
J=\sum_{l=0}^{N_{p-1}}\left(\tilde{u}(k+l)^{T} Q_{u} \tilde{u}(k+l)+f^{T} \tilde{u}(k+l)\right)+ \\
\sum_{l=0}^{N_{p-1}}\left(\tilde{x}(k+l)-\tilde{x}_{r e f}(k+l)\right)^{T} Q_{x}\left(\tilde{x}(k+l)-\tilde{x}_{r e f}(k+l)\right)
\end{array}
$$

s.t.

$$
\begin{gathered}
\frac{x}{u} \leq \tilde{x}(k+l+1) \leq \bar{x} \\
\underline{u} \leq \tilde{u}(k+l+1) \leq \bar{u} \\
\tilde{y}(k+l)=\operatorname{Load}(k) \\
\tilde{u}(k+l)=P_{\text {solar }}(k)=P_{P V_{\text {available }}}(k) \\
x(k)=\tilde{x}(k)
\end{gathered}
$$

for $l=0, \ldots, N_{p}-1$. Where $Q_{u}$ and $Q_{u}$ are positive definite weghting matrices and $f$ is a linear function, $N_{p}$ is the prediction horizon. Regarding notation " $\tilde{a}$ " over variables is used to denote variables over the prediction horizon, $a_{i}$ and $\overline{a_{i}}$ denote minimum and maximum allowed values respectively, and $\check{a}_{i}$ refers to variables which values are supposed to be know, for example, initial conditions.

In order to ensure proper use of renewable energy sources, making the purchase and sale management of electricity to the utility grid and using the storage to minimize the oscillations between the production and demand, binary variables are introduced as constraints in the formulations as follow:

$$
\begin{aligned}
& \delta_{\text {GridPurch }}(k)= \begin{cases}1 & P_{\text {GridPurch }}(k)>0 \\
0 & P_{\text {GridPurch }}(k)=0\end{cases} \\
& \delta_{\text {Gridscale }}(k)= \begin{cases}1 & P_{\text {Gridsale }}(k)>0 \\
0 & P_{\text {Gridsale }}(k)=0\end{cases} \\
& \delta_{\text {GridPurch }}(k)+\delta_{\text {GridSale }}(k)=1 \\
& \delta_{B A T_{C H}}(k)= \begin{cases}1 & P_{B A T_{C H}}(k)>0 \\
0 & P_{B A T_{C H}}(k)=0\end{cases} \\
& \delta_{B A T_{D I S C H}}(k)= \begin{cases}1 & P_{B A T_{D I S C H}}(k)<0 \\
0 & P_{B A T_{D I S C H}}(k)=0\end{cases} \\
& \delta_{B A T_{C H}}(k)+\delta_{B A T_{D I S C H}}(k)=1
\end{aligned}
$$

The state space formulation of a hub has been transformed into the Mixed Logical Dynamic (MLD) formulation considering concepts of propositional calculus and integer linear programming as is showed in [20], this formulation make it possible to include binary variables introduced in a discrete-time dynamic system in order to describe, in a unified model, the evolution of the continuous and logic signals of the system. The conditions $P_{j}>0$ in the equations (21), (22) y (24) and the condition $P_{B A T_{D I S C H}}<0$ in the equation (25) can be associated to a binary variable $\delta_{j}$ for $j=$ $\left\{\right.$ GridPurch, GridSale, $\left.B A T_{D I S C H}\right\} \quad$ and $\quad \delta_{B A T_{D I S C H}}$, respectively, such that

$$
\begin{gathered}
{\left[P_{j}(k)>0\right] \rightarrow\left[\delta_{j}(k)=1\right]} \\
{\left[P_{B A T_{D I S C H}}<0\right] \rightarrow\left[\delta_{B A T_{D I S C H}}(k)=1\right]}
\end{gathered}
$$

The equations (27) can be expressed by the inequalities

$$
\begin{gathered}
(M+\epsilon) \delta_{j}(k)-P_{j} \delta_{j}(k)>0 \\
(m+\epsilon) \delta_{B A T_{D I S C H}}(k)-P_{B A T_{D I S C H}} \delta_{B A T_{D I S C H}}(k)<0
\end{gathered}
$$

Where

$$
\begin{aligned}
& m=\min P_{B A T_{D I S C H}}(k) \\
& M=\max P_{j}(k)
\end{aligned}
$$

And $\epsilon$ is a small tolerance (typically the machine precision).

In the equation (21), when $P_{\text {GridPurch }}(k)>0$ we have $\delta_{\text {GridPurch }}(k)=1$, wich means that the energy is purchased to grid and therefore the weight is use on the value of purchased, in (22), when $P_{\text {Gridscale }}(k)>0$ we have $\delta_{\text {Gridscale }}(k)=1$, wich means that is use on the value of sale. Analogously analysis is performed for equations (24) and (25). Furthermore, the equations (23) and (26) are associated to exclusive sum (exclusive or), such that

$$
\begin{gathered}
{\left[P_{\text {GridPurch }}(k) \oplus P_{\text {GridSale }}(k)\right]} \\
{\left[P_{B A T_{C H}}(k) \oplus P_{B A T_{D I S C H}}(k)\right]}
\end{gathered}
$$

This means that only one action can be performed at once, buying or selling energy and charging or discharging energy of the batteries.

In addition, economic aspects of buying and selling energy have been considered in the objective function, as follows

$$
\begin{aligned}
J= & \sum_{l=0}^{N_{p-1}}\left(-\Upsilon_{\text {sale }}(k+l) \cdot P_{\text {GridSale }}(k+l)+\Upsilon_{\text {Purch }}(k+l)\right. \\
& \left.P_{\text {GridPurch }}(k+l)\right) \cdot T_{s}
\end{aligned}
$$

for $l=0, \ldots, N_{p}-1$. Where $\Upsilon_{\text {sale }}$ and $\Upsilon_{\text {Purch }}$ are the purchase and sale price of energy, respectively.

\section{Results}

In order to verify how the proposed controller behaves, it has been run a simulation with real data collected for a sunny day and a day with passing clouds.

It is considered that we have 3 similar sets of batteries and 10 similar greenhouses that have been presented in the materials section; the cost of degradation of the batteries and the maintenance cost of the photovoltaic system have not been considered.

The first term of the objective function (equation (15)) have been used for the management of renewable sources and the purchase/sale of energy from the utility grid. The weights $Q_{u}$ and $f$ are tuned according to the price of energy and the use of batteries, the weights for buying and selling energy can be seen in Figure 13 and the 
charging and discharging weights have been assigned equal to the weight assigned for power purchase. In the second term, $Q_{x}$ has been tuned to maintain the value of SOC around of $50 \%$ and permitting deviation around this value. The controller was implemented in MATLAB [21] using the toolbox YALMIP [22] and the solver CPLEX [23].

The Figures 7 and 10 shown the amount of solar energy available, as well as the amount of energy used to charge and discharge of the batteries, moreover, the energy flow between the microgrid and the utility grid is shown for a sunny day and a day with passing clouds, respectively. In the Fig. 7 it can be seen that energy is allowed to sell between 10 and 15 hours, this is due to it has a surplus of energy and the batteries are located around the reference trying to maintain (see Figure 8) and the demand falls dramatically (see Figure 9), whereas that in Fig. 10 it is allowed to sell little and instead use more of the batteries. In the Figures 8 and 11 it can be seen the SOC batteries, the controller tends to maintain the amount of stored energy in 50\% allowing fluctuations at times where there is no renewable energy enough to attend the demand. In Figures 9 and 12 energy demands of both days are shown. The Figure 13 shows the energy price. The Table I shown the energy exchanged with the utility grid using the controller.

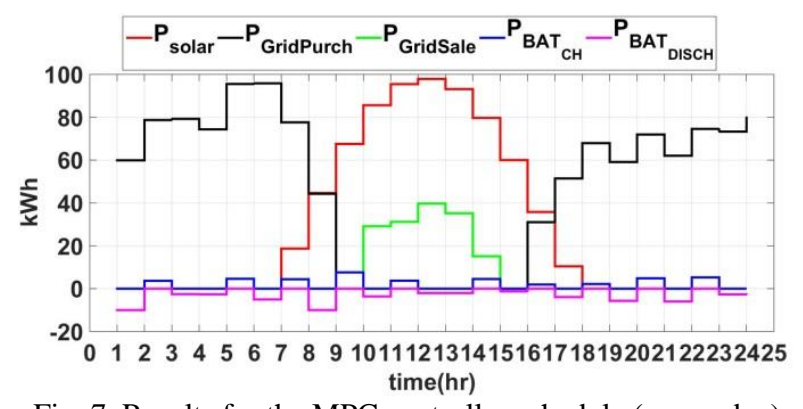

Fig. 7. Results for the MPC controller schedule (sunny day).

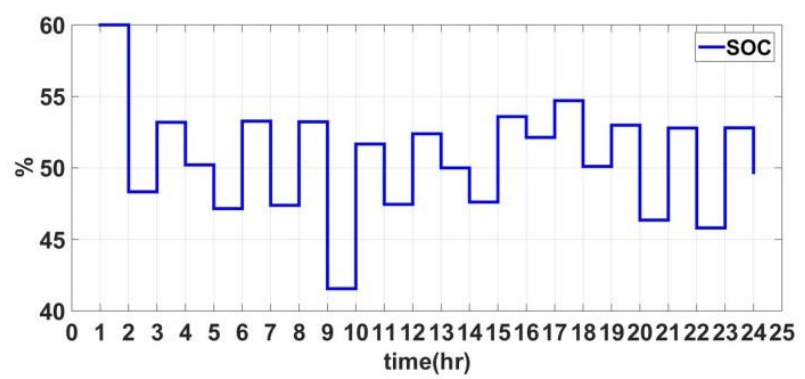

Fig. 8. State of Charge of batteries (sunny day).

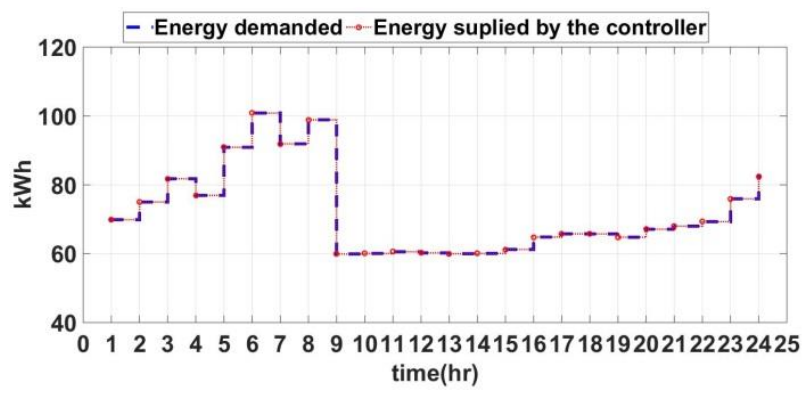

Fig. 9. Energy demanded and supplied by the controller (sunny day).

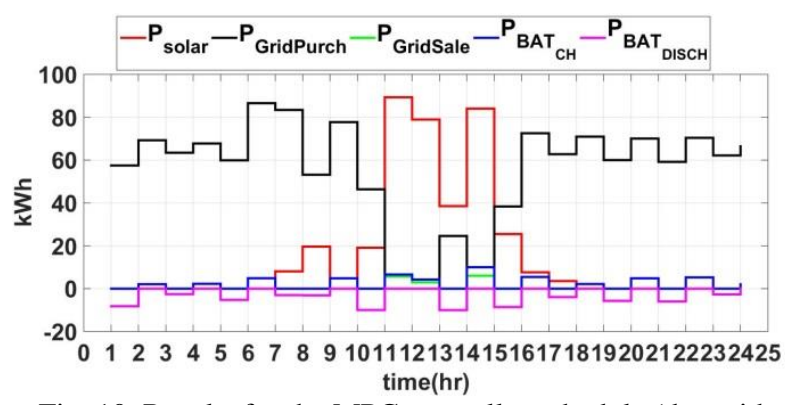

Fig. 10. Results for the MPC controller schedule (day with passing clouds).

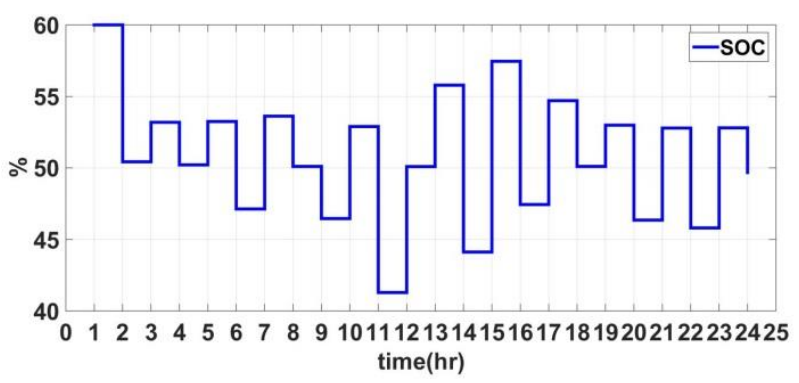

Fig. 11. State of Charge of batteries (day with passing clouds).

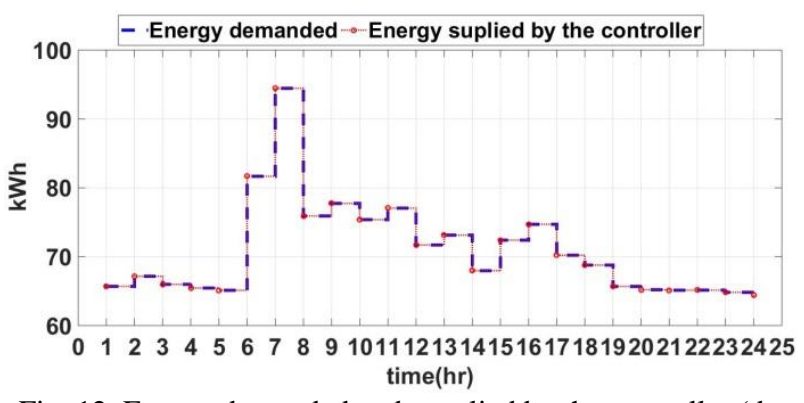

Fig. 12. Energy demanded and supplied by the controller (day with passing clouds).

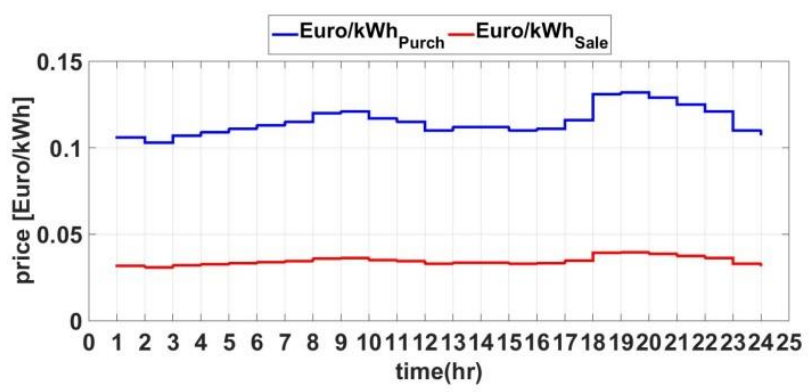

Fig. 13. Energy price.

Table I. - Energy (kWh) exchanged with the utility grid.

\begin{tabular}{|c|c|c|c|c|}
\hline $\begin{array}{c}\text { Day } \\
\text { type }\end{array}$ & $\begin{array}{c}\text { Energy } \\
\text { purchased }\end{array}$ & $\begin{array}{c}\text { Cost of } \\
\text { purchase } \\
(€)\end{array}$ & $\begin{array}{c}\text { Energy } \\
\text { sold }\end{array}$ & $\begin{array}{c}\text { Benefit } \\
\text { of sale } \\
(€)\end{array}$ \\
\hline Sunny & 1096.4 & 126.8 & 150.2 & 8.5 \\
\hline $\begin{array}{c}\text { With } \\
\text { clouds }\end{array}$ & 1255.7 & 145.9 & 14.6 & 0.8 \\
\hline
\end{tabular}

As it has been observed, the weights have been assigned heuristically and the controller behavior may vary depending on the intended use to the different energy sources. As the selling price of energy is very low, we may decide that instead of selling the energy would be stored. 


\section{Conclusions and future work}

In this article a controller has been implemented in order to optimize the use of renewable energies in a microgrid and see the behavior of the controller. The controller has been implemented to perform the use of batteries where charging and discharging are allowed with an oscillation around a desired load value. It has also been considered buying and selling energy to the utility grid with the price of energy varying in time. The results are derived from a simulation carried out during two days (a sunny day and a day with passing clouds). For future work, demand forecasting, energy production and price forecasting models based on time series as an ARIMA, ARMAX and Neural Networks will be introduced, moreover, the results will be improved by adjusting the parameters of the controller.

\section{Acknowledgement}

This work has been funded by the National R+D+I Plan Project DPI2014-56364-C2-1-R of the Spanish Ministry of Economy and Competitiveness and ERDF funs.

\section{References}

[1] A. Karabiber, C. Keles, A. Kaygusuz, and B. B. Alagoz, "An approach for the integration of renewable distributed generation in hybrid DC/AC microgrids," Renew. Energy, vol. 52, pp. 251-259, 2013.

[2] M. S. Carmeli, F. Castelli-Dezza, M. Mauri, G. Marchegiani, and D. Rosati, "Control strategies and configurations of hybrid distributed generation systems," Renew. Energy, vol. 41, pp. 294-305, 2012.

[3] K. Kurohane, A. Uehara, T. Senjyu, A. Yona, N. Urasaki, T. Funabashi, and C.-H. Kim, "Control strategy for a distributed DC power system with renewable energy," Renew. Energy, vol. 36, no. 1, pp. 42-49, 2011.

[4] H. Morais, P. Kádár, P. Faria, Z. A. Vale, and H. M. Khodr, "Optimal scheduling of a renewable micro-grid in an isolated load area using mixedinteger linear programming," Renew. Energy, vol. 35 , no. 1, pp. 151-156, 2010.

[5] E. Dursun and O. Kilic, "Comparative evaluation of different power management strategies of a stand-alone PV/Wind/PEMFC hybrid power system," Int. J. Electr. Power Energy Syst., vol. 34, no. 1, pp. 81-89, 2012.

[6] B. Indu Rani, G. Saravana Ilango, and C. Nagamani, "Power flow management algorithm for photovoltaic systems feeding DC/AC loads," Renew. Energy, vol. 43, pp. 267-275, 2012.

[7] H. Chitsaz, H. Shaker, H. Zareipour, D. Wood, and N. Amjady, "Short-term Electricity Load Forecasting of Buildings in Microgrids," Energy Build., vol. 99, pp. 50-60, Apr. 2015.

[8] W. Huang, M. Lu, and L. Zhang, "Survey on microgrid control strategies," Energy Procedia, vol. 12, pp. 206-212, 2011.
[9] A. Etxeberria, I. Vechiu, H. Camblong, and J.-M. Vinassa, "Hybrid energy storage systems for renewable energy sources integration in microgrids: A review," in IPEC, 2010 Conference Proceedings, 2010, pp. 532-537.

[10] M. H. Nehrir, C. Wang, K. Strunz, H. Aki, R. Ramakumar, J. Bing, Z. Miao, and Z. Salameh, "A review of hybrid renewable/alternative energy systems for electric power generation: Configurations, control, and applications," Sustain. Energy, IEEE Trans., vol. 2, no. 4, pp. 392-403, 2011.

[11] W. Gu, Z. Wu, and X. Yuan, "Microgrid economic optimal operation of the combined heat and power system with renewable energy," IEEE Power Energy Soc. Gen. Meet., pp. 1-6, 2010.

[12] H. Karami, M. J. Sanjari, S. H. Hosseinian, and G. B. Gharehpetian, "An Optimal Dispatch Algorithm for Managing Residential Distributed Energy Resources," IEEE Trans. Smart Grid, vol. 5, no. 5, pp. 2360-2367, Sep. 2014.

[13] G. Ferrari-Trecate, E. Gallestey, P. Letizia, M. Spedicato, M. Morari, and M. Antonine, "Modeling and control of co-generation power plants: a hybrid system approach," IEEE Trans. Control Syst. Technol., vol. 12, no. 5, pp. 694705, 2004

[14] L. Valverde, C. Bordons, and F. Rosa, "Power Management using Model Predictive Control in a hydrogen-based microgrid," Annu. Conf. IEEE Ind. Electron. Soc., pp. 5669-5676, 2012.

[15] E. F. Camacho and C. B. Alba, Model predictive control. Springer Science \& Business Media, 2013.

[16] M. Geidl, G. Koeppel, P. Favre-Perrod, B. Klockl, G. Andersson, and K. Frohlich, "Energy hubs for the future," IEEE Power Energy Mag., vol. 5 , no. 1 , p. $24,2007$.

[17] M. Geidl and G. Andersson, "A modeling and optimization approach for multiple energy carrier power flow," in Power Tech, 2005 IEEE Russia, 2005, pp. 1-7.

[18] P. R. da C. Mendes, J. E. Normey-Rico, and C. B. Alba, "Economic energy management of a microgrid including electric vehicles," in Innovative Smart Grid Technologies Latin America (ISGT LATAM), 2015 IEEE PES, 2015, pp. 869-874.

[19] P. R. C. Mendes, L. V. Isorna, C. Bordons, and J. E. Normey-Rico, "Energy management of an experimental microgrid coupled to a V2G system," J. Power Sources, vol. 327, pp. 702713, 2016.

[20] A. Bemporad and M. Morari, "Control of systems integrating logic, dynamics, and constraints," Automatica, vol. 35, no. 3, pp. 407427, 1999.

[21] MATLAB, version 8.4.0 (R2014b). The MathWorks Inc., 2014.

[22] J. Lofberg, "YALMIP : A Toolbox for Modeling and Optimization in MATLAB.," in CACSD Conference, Taipei, Taiwan., 2004.

[23] ILOG, “CPLEX," 2007. 